\title{
EDUCAÇÃO PATRIMONIAL PARA ARQUEÓLOGOS: REPENSANDO PRÁTICAS E CRIANDO NOVOS CAMINHOS
}

Cristiane Eugênia Amarante ${ }^{1}$

\section{RESUMO}

Este artigo é sobre um curso de educação patrimonial oferecido para o público em geral que visava apresentar um histórico da educação patrimonial voltada para a arqueologia no Brasil discutindo suas práticas e contextos. Os inscritos foram todos arqueólogos graduados ou pós-graduados. O público possibilitou a análise de questões sobre a interface entre educação e arqueologia. As discussões geraram novas reflexões sobre a gestão do patrimônio arqueológico no Brasil e a necessidade de conhecimentos de educação por parte dos arqueólogos. Dentro da perspectiva da arqueologia pública, a educação patrimonial é parte intrínseca ao processo de pesquisa. A educação nesse sentido tem a função de oferecer ferramentas às pessoas para que elas avaliem as evidências arqueológicas e tirem suas próprias conclusões.

Palavras-chave: educação patrimonial, arqueologia pública, museus de arqueologia, arqueologia de contrato, formação de arqueólogos.

\section{ABSTRACT}

This paper is about a patrimonial education course available to a general audience, which intended to present a detailed description of heritage education turned to archeology in Brazil, discussing its practices and contexts. All enrolled participants were graduate and postgraduate students in archeology. The audience enabled the analysis of issues on the interface between education and archeology. The discussions led to new reflections on the archeological heritage management in Brazil and the need of education knowledge by archeologists. Under the public archeology perspective, heritage education is a particular portion in the research process. In this sense, education has the function of offering people the tools needed to evaluate the archeological evidences and reach their own conclusions.

Keywords: heritage education, public archaeology, archeological museums, contract archeology, training of archaeologists.

\section{RESUMEN}

Este artículo se refiere a un curso de educación patrimonial ofrecido al público general con el fin de presentar un historial de la educación patrimonial dirigida para la arqueología en Brasil y de discutir sus prácticas y contextos. Todos los inscriptos eran arqueólogos licenciados o con posgrado. El público permitió realizar un análisis de cuestiones relativas a la interface entre educación y arqueología. Las discusiones han producido nuevas reflexiones respecto a la gestión del patrimonio arqueológico en Brasil y a la necesidad de conocimientos sobre educación por parte de los arqueólogos. Desde la perspectiva de la

${ }^{1}$ Doutoranda em Arqueologia pela Universidade Federal de Sergipe - UFS, bolsista CAPES. Contato: criseugenia.arqueo@gmail.com 


\section{Revista de Arqueologia Pública}

arqueología pública, la educación patrimonial es una parte intrínseca del proceso de investigación. La educación en ese sentido tiene la función de proporcionar herramientas a las personas para que ellas evalúen las evidencias arqueológicas y lleguen a sus propias conclusiones.

Palabras clave: educación patrimonial, arqueología pública, museos arqueológicos, arqueología del contrato, la formación de arqueólogos.

\section{Agradecimentos}

Agradeço à Contextos Arqueologia, onde foi possível oferecer o curso: Educação Patrimonial e Arqueologia - Teoria e Prática, de onde vieram as reflexões apresentadas neste artigo. Agradeço aos colegas arqueólogos que fizeram com que o curso se realizasse: Roberval de Souza Júnior, Sálvio Henrique Costa, Adriano Batista, Marcus Mattos, Eva Simões e Fernanda Libório.

\section{Introdução}

Este artigo tem como base um curso realizado pela Contextos Arqueologia, uma empresa de arqueologia de Aracaju-SE, que além dos licenciamentos ambientais também trabalha com a formação de arqueólogos e não arqueólogos em temas atuais da arqueologia brasileira. O curso foi realizado em três dias consecutivos, em junho de 2015, com 4 horas diárias de aula. Todos os inscritos eram arqueólogos graduados, mestres e mestrandos.

Um dos pressupostos do curso era que os participantes tivessem contato com diferentes práticas de ação educativa em arqueologia. É importante destacar isso, pois em muitos momentos a educação patrimonial acaba se confundindo com questões da preservação do patrimônio, tais como, patrimônio imaterial e patrimônio edificado em detrimento do patrimônio arqueológico. Não podemos perder de vista que a educação patrimonial desenvolvida por nós pode dialogar com outras manifestações culturais, mas a arqueologia tem que estar sempre presente.

Para esta autora, ministrar o curso a um grupo composto somente por arqueólogos foi uma experiência nova, uma vez que já havia orientado cursos de educação patrimonial para outros públicos como professores, guias turísticos, e pessoas da comunidade em geral. Também havia dirigido diversas oficinas de educação patrimonial para crianças. $A$ vivência do curso para arqueólogos se mostrou ser um grande desafio, e ao mesmo tempo trouxe aprendizados e reflexões. 


\section{Revista de Arqueologia Pública}

\section{Considerações iniciais}

A história desta autora em relação à educação patrimonial está relacionada à sua formação inicial e à experiência profissional. A autora possui graduação em história e pedagogia, concluídas em duas universidades privadas de Santos - SP e é mestra em arqueologia pelo Museu de Arqueologia e Etnologia da Universidade de São Paulo (MAE USP) e atualmente cursa doutorado em Arqueologia na Universidade Federal de Sergipe (UFS).

Profissionalmente, entrou para o mundo da arqueologia pelas portas da educação. Atuou como educadora patrimonial no Engenho São Jorge dos Erasmos, em Santos - SP, por três anos consecutivos. No Engenho, ela e Adriana Negreiros Campos, também mestra em arqueologia pelo MAE USP, organizaram ações educativas com enfoque na arqueologia, uma vez que o local se trata das ruínas de um engenho quinhentista (1534) e, portanto, um importante sítio arqueológico. A ação era uma parceria entre a Universidade de São Paulo e a Secretaria Municipal de Educação de Santos (da qual faziam parte).

Também teve as experiências da pós-graduação lato sensu em Ciências Humanas, pelo Centro de Extensão Universitária, em que realizou um trabalho de formação de professores da educação de jovens e adultos em Santos - SP com enfoque na educação patrimonial voltada à cultura material, com orientação do arqueólogo doutor Pedro Paulo A. Funari. No mestrado foi orientada pela museóloga doutora Marília Xavier Cury, utilizando na sua pesquisa estratégias de educação para a realização de um estudo de recepção com coletas de dados, visando a criação de um museu marítimo para a cidade de Santos-SP.

Essas experiências fizeram com que o diálogo da autora com as temáticas da educação e arqueologia fossem ampliando e ganhando novas dimensões à medida que os estudos se aprofundavam.

\section{Questões teóricas}

A educação patrimonial vai muito além das exigências de legislação. Pelo olhar da arqueologia pública, a educação deve ser um diálogo com o público não acadêmico em que as pessoas devem conhecer a arqueologia nos seus métodos e enquanto ciência tirarem suas próprias conclusões.

Arqueologia Pública foi um termo utilizado por McGimsey, em uma publicação de mesmo nome, em 1972. Sumariamente significa arqueologia para o público. Mais tarde, 


\section{Revista de Arqueologia Pública}

Nick Merriman definiu melhor o termo, afirmando que se refere a quando o Estado assume o papel de falar ao público sobre assuntos e ações de interesses públicos (MERRIMAN, 2004: 1). O processo, na visão do autor, acontece por meio de instituições e serviços de arqueologia, museu e educação.

Mas, para Merriman o termo público é incompleto, porque não contempla a diversidade de idades, gêneros, classes, etnicidades, interesses religiosos e outros. Além disso, ele considera que a arqueologia atua em um campo de conflito, e por isso, deve expor interesses discordantes na diversidade, inclusive com o Estado. Por fim, defende que a interpretação da cultura material é um ato político.

Então, levando-se esses aspectos em consideração, esta autora considera que a educação nesse viés deve ser entendida também como ato político, e adota como princípio teórico o construtivismo. Essa opção está em consonância com Merriman que aponta as teorias do construtivismo do campo da educação como caminho para o diálogo entre arqueólogos e públicos como modelo para museus e sítios musealizados.

Os teóricos desta corrente educacional defendem que o indivíduo pode construir seu próprio saber com o auxílio de outros à sua volta. Os autores que oferecem suporte para os trabalhos desta autora são Piaget, um dos primeiros a compreender a construção do conhecimento pelo indivíduo (PIAGET, 1974; 1973; 1971; 1967; 1966); Vygotsky, que se dedicou a estudar a construção de conhecimento nas interações humanas (VYGOTSKY, 1996; 1998); Paulo Freire, que trabalhou e construiu um método visando a formação do sujeito capaz de agir sobre sua própria história e sobre a comunidade (FREIRE, 1987; 1997); Jonh Dewey, criador do escolanovismo, ou seja, a escola como espaço para aprendizados sobre a vida social (DEWEY, 1932; 1971); e Fernando Hernandez, que elaborou a pedagogia de projetos, em que o estudante é o autor do próprio conhecimento orientado pelo professor (HERNANDEZ e VENTURA, 1998a; 1998b). Todos esses conceitos dialogam bem com os pressupostos da arqueologia pública.

Outra área do conhecimento que também interage com a arqueologia é a museologia. O movimento da nova museologia, assim como a arqueologia pública, se preocupa com o público. Essas áreas, bem como suas teorias podem contribuir para a elaboração de novas práticas.

No novo modelo de museu, a decisão é cooperativa e o público participa mais. As decisões continuam sendo responsabilidade dos profissionais do museu, mas não como donos da verdade. A equipe tem que facilitar a participação do público (CURY, 2005). Cury faz uma descrição de museólogos, que se acredita encaixarem bem para arqueólogos. De 


\section{Revista de Arqueologia Pública}

serem arrojados, assumindo riscos e se colocando distantes das antigas posições fechadas, categóricas e autoritárias.

Para auxiliar a compreensão de como se dá os estudos a respeito da interrelação entre arqueologia-educação-museologia, observou-se a produção acadêmica da Universidade de São Paulo sobre os temas.

A tabela abaixo mostra teses e dissertações que se relacionam ao tema educação e museus.

\begin{tabular}{|l|l|l|}
\hline \multicolumn{1}{|c|}{ Autor } & \multicolumn{1}{|c|}{ Ano } & \multicolumn{1}{c|}{ Título } \\
\hline $\begin{array}{l}\text { BRUNO, } \\
\text { Maria } \\
\text { Oliveira }\end{array}$ & $\begin{array}{l}1984 \\
\text { FFLCH - USP }\end{array}$ & $\begin{array}{l}\text { Dissertação: } \\
\text { O museu do Instituto de Pré-História: um museu a } \\
\text { serviço da pesquisa científica }\end{array}$ \\
\hline $\begin{array}{l}\text { TAMANINI, } \\
\text { Elizabete }\end{array}$ & $\begin{array}{l}1994 \\
\text { FE } \\
\text { UNICAMP }\end{array}$ & $\begin{array}{l}\text { Dissertação: } \\
\text { Museu Arqueológico de Sambaqui: um olhar } \\
\text { necessário }\end{array}$ \\
\hline $\begin{array}{l}\text { CURY, } \\
\text { Marília Xavier }\end{array}$ & $\begin{array}{l}2005 \\
\text { ECA - USP }\end{array}$ & $\begin{array}{l}\text { Tese: } \\
\text { Comunicação museológica: uma perspectiva teórica } \\
\text { e metodológica de recepção }\end{array}$ \\
\hline $\begin{array}{l}\text { CORDEIRO, } \\
\text { Sílvio Luiz }\end{array}$ & $\begin{array}{l}2007 \\
\text { MAE - USP }\end{array}$ & $\begin{array}{l}\text { Dissertação: } \\
\text { A paisagem histórica do Engenho São Jorge dos } \\
\text { Erasmos: o vídeo como instrumento educativo na } \\
\text { arqueologia do monumento quinhentista }\end{array}$ \\
\hline $\begin{array}{l}\text { TAUHYL, } \\
\text { Ana Paula Moreli }\end{array}$ & MAE - USP & $\begin{array}{l}\text { Dissertação: } \\
\text { Alfabetização do olhar: aprender pelos objetos e } \\
\text { suas representações }\end{array}$ \\
\hline $\begin{array}{l}\text { CAMPOS, } \\
\text { Adriana Negreiros }\end{array}$ & $\begin{array}{l}2014 \\
\text { MAE - USP }\end{array}$ & $\begin{array}{l}\text { Dissertação: } \\
\text { Arqueologia e educação: as Ruínas Engenho São } \\
\text { Jorge dos Erasmos como fio condutor de práticas } \\
\text { educacionais }\end{array}$ \\
\hline $\begin{array}{l}\text { AMARANTE, } \\
\text { Cristiane Eugênia } \\
\text { Leilane Patrícia de }\end{array}$ & $\begin{array}{l}2015 \\
\text { MAE - USP }\end{array}$ & $\begin{array}{l}\text { Tese: A arqueologia e os indígenas na escola: um } \\
\text { estudo de público em Londrina / PR } \\
\text { Reflexões sobre musealização: um encontro entre } \\
\text { público e arqueologia marítima em Santos }\end{array}$ \\
\hline
\end{tabular}

A primeira dissertação sobre o tema foi elaborada por Cristina Bruno (USP), em 1984. A pesquisa versava sobre as ações educativas do antigo Instituto de Pré-História 


\section{Revista de Arqueologia Pública}

(hoje Museu de Arqueologia e Etnologia da Universidade de São Paulo - MAE USP) (BRUNO, 1984). A segunda pesquisa sobre o assunto foi a dissertação de Elizabete Tamanini, dez anos depois, em 1994, na Universidade Estadual de Campinas (UNICAMP). A pesquisa, entre outros aspectos, abordava as ações educativas do Museu do Sambaqui de Joinville (TAMANINI, 1994). Embora esta última seja a única da lista que não faz parte da Universidade de São Paulo, achou-se pertinente incluí-la, pois ambas tratam sobre os primeiros trabalhos de educação patrimonial em museus de arqueologia no Brasil, servindo como base e inspiração para iniciativas posteriores.

A terceira foi a tese de Marília Xavier Cury, onze anos depois, em 2005. Na tese ela discutiu a elaboração da exposição do Museu de Água Vermelha, em Ouroeste, no interior de São Paulo, a partir de um estudo de recepção com estudantes (CURY, 2005).

Em 2007, tem-se a dissertação de Sílvio Cordeiro, sobre um trabalho de educação utilizando vídeo, no Engenho dos São Jorge dos Erasmos em Santos - SP (CORDEIRO, 2007). Esta pesquisa se diferencia das demais, pois possui um aspecto inovador, o uso do vídeo como instrumento de educação.

Em 2013, observamos a dissertação de Ana Paula Tauhyl, sobre o uso educativo das maquetes clássicas do Museu de Arqueologia e Etnologia da Universidade de São Paulo (MAE USP) (TAUHYL, 2013).

Em 2014, foram defendidas duas dissertações, a desta autora (AMARANTE, 2014) e a de Adriana Negreiros Campos que realizou e analisou um processo prolongado de educação patrimonial no Engenho dos Erasmos em Santos - SP tendo como grupo colaborador estudantes e pais de uma escola municipal (CAMPOS, 2014).

Por fim, em 2015, foi defendida a tese de Leilane Lima. Um estudo de público em Londrina - PR (LIMA, 2015).

Acredita-se que a contribuição dos museus de arqueologia para o desenvolvimento da educação patrimonial foi imprescindível. Eles se tornaram pólos de aplicação e difusão de práticas bastante inovadoras de aproximação com o público. Eles também iniciaram os debates teóricos, procurando compreender os pensamentos norteadores das práticas educativas e expositivas tanto trazidas de fora do país como as construídas internamente, principalmente as práticas com fundamentação em Paulo Freire.

A respeito da arqueologia de contrato, observa-se que ela muito se embasou nos conhecimentos produzidos pelos museus de arqueologia.

A partir de 2002, a portaria 230 criou a obrigatoriedade da educação patrimonial nos licenciamentos ambientais. Ao ser obrigado a desenvolver trabalhos de educação patrimonial, parte dos arqueólogos recorreu ao guia do IPHAN, de 1999, de Maria de 


\section{Revista de Arqueologia Pública}

Lourdes Parreiras Horta, Evelina Grumberg e Adriane Queiróz Monteiro (HORTA et al, 1999). Esse guia possuía práticas trazidas da Inglaterra na década de 1980 e aplicadas em alguns museus brasileiros, como o Museu Imperial de Petrópolis, por exemplo. Aos poucos algumas empresas de arqueologia, em diálogo com os museus, foram amadurecendo as práticas, conforme observamos nas pesquisas da tabela a seguir.

\begin{tabular}{|c|c|c|}
\hline Autor & Ano & Título \\
\hline $\begin{array}{l}\text { ALMEIDA, } \\
\text { Márcia Bezerra }\end{array}$ & $\begin{array}{l}2002 \\
\text { MAE - USP }\end{array}$ & $\begin{array}{l}\text { Tese: } \\
\text { O australopiteco corcunda: as crianças e a } \\
\text { arqueologia em um projeto de arqueologia pública na } \\
\text { escola. }\end{array}$ \\
\hline $\begin{array}{l}\text { FERNANDES, } \\
\text { Tatiana Costa }\end{array}$ & $\begin{array}{l}2007 \\
\text { MAE - USP }\end{array}$ & $\begin{array}{l}\text { Dissertação: } \\
\text { Vamos criar um sentimento?: } \\
\text { Um olhar sobre a arqueologia pública no Brasil }\end{array}$ \\
\hline $\begin{array}{l}\text { CARNEIRO, } \\
\text { Carla Gibertoni }\end{array}$ & $\begin{array}{l}2009 \\
\text { MAE - USP }\end{array}$ & $\begin{array}{l}\text { Tese: } \\
\text { Ações educacionais no contexto da arqueologia } \\
\text { preventiva: uma proposta para a Amazônia }\end{array}$ \\
\hline $\begin{array}{l}\text { MORAES WICHERS, } \\
\text { Camila Azevedo }\end{array}$ & $\begin{array}{l}2011 \\
\text { MAE - USP }\end{array}$ & $\begin{array}{l}\text { Tese: } \\
\text { Patrimônio arqueológico paulista: proposições e } \\
\text { provocações arqueológicas }\end{array}$ \\
\hline $\begin{array}{l}\text { ALFONSO, } \\
\text { Louise Prado }\end{array}$ & $\begin{array}{l}2013 \\
\text { MAE - USP }\end{array}$ & $\begin{array}{l}\text { Tese: } \\
\text { Arqueologia e turismo: } \\
\text { sustentabilidade e inclusão social }\end{array}$ \\
\hline
\end{tabular}

A primeira tese foi escrita por Márcia Bezerra Almeida, em 2002: O australopiteco corcunda. A pesquisa foi desenvolvida em uma escola privada do Rio de Janeiro - RJ (ALMEIDA, 2002). Em 2007, foi defendida a dissertação da Tatiana Costa Fernandez: Vamos criar um sentimento (FERNANDES, 2007). A autora denomina suas práticas como sendo de etnoarqueologia, mas compreende-se que ela dialoga com a arqueologia pública e a educação patrimonial.

Em 2009, foi defendida a tese de Carla Gibertoni Carneiro, sobre ações educativas na Amazônia (CARNEIRO, 2009). Em 2011, Camila Azevedo Moraes Wichers defendeu sua tese sobre patrimônio arqueológico paulista (MORAES WICHERS, 2011). Embora o principal tema da pesquisa fosse museus, o contexto era de arqueologia de contrato. E por 


\section{Revista de Arqueologia Pública}

fim, tem-se a tese de Louise Prado Alfonso, sobre arqueologia e turismo (ALFONSO, 2013). Dentro da arqueologia de contrato ela trabalhou com a elaboração de uma exposição em Lins (caso que observei mais detalhadamente). Ela desenvolveu ações junto à comunidade local (ALFONSO e HATTORI, 2013).

As teses e dissertações sobre educação patrimonial na arqueologia de contrato são mais recentes e estão em número menor. Têm-se oito pesquisas sobre educação patrimonial em museus de arqueologia e cinco sobre educação patrimonial na arqueologia de contrato. Outra questão é que as pesquisadoras que apresentaram pesquisas sobre a educação no licenciamento ambiental possuem suas histórias pessoais ligadas ao museu, principalmente, o Museu de Arqueologia e Etnologia da Universidade de São Paulo. A constatação demonstra a influência das práticas educativas dos museus nas ações do contrato.

\section{Desenvolvimento e metodologia}

O curso possuía uma pauta a ser desenvolvida, recebida pelos participantes logo no início para acompanhamento do desenvolvimento dos encontros. Em todos os dias, havia uma leitura de sensibilização e uma parte teórica. Em seguida, o foco eram os estudos de caso. Após o intervalo, se fazia uma atividade prática e uma finalização das atividades do dia.

Os módulos foram organizados da seguinte maneira: Módulo 1 - Metodologias da Educação Patrimonial; Módulo 2 - Educação Patrimonial nos Museus de Arqueologia e Módulo 3 - Educação Patrimonial na Arqueologia de Contrato.

No primeiro encontro, discutiram-se metodologias da educação patrimonial. Metodologias estavam no plural, pois se consideraram mais de uma metodologia, com diferentes bases teóricas, técnicas e métodos.

A princípio se apresentou a metodologia da educação patrimonial trazida da Inglaterra para o Brasil, por Maria de Lourdes Parreiras Horta na década de 1980 (HORTA et al, 1999). A mesma possui as etapas de observação, registro, exploração e apropriação. Como ela é a mais conhecida, não podia ser ignorada. Além disso, suas estratégias ainda são base para diferentes trabalhos de educação patrimonial em arqueologia.

No decorrer deste primeiro encontro, expandiram-se as estratégias para outras abordagens como o hereduc, uma metodologia também de quatro etapas, criada no início dos anos 2000 por educadores que trabalhavam com patrimônio na Comunidade Europeia (TROYLER, 2010). É importante lembrar que em países como Itália, Inglaterra, França e 


\section{Revista de Arqueologia Pública}

Holanda, a educação patrimonial faz parte do currículo do ensino regular. As quatro etapas do hereduc são: ponto de entrada, enchendo sua mochila, desenvolvendo uma solução e resultados.

Iniciaram-se os estudos de caso do primeiro encontro, apresentando-se o Roteiro Arqueológico desenvolvido por esta autora e por Adriana Negreiros Campos na cidade de Santos-SP.

Nesse roteiro, adaptou-se o conhecido roteiro histórico. Passou-se a trabalhar com um roteiro arqueológico na perspectiva de se reconhecer "o que não existe mais". $\mathrm{Na}$ verdade, não aos nossos olhos, mas os vestígios existem embaixo dos nossos pés!

Nessa perspectiva, orientaram-se professores, guias turísticos, comunidade e crianças. Um dos aspectos trabalhados era a percepção das permanências e mudanças. Uma das atividades desenvolvidas pelos participantes do roteiro arqueológico era a montagem de um quebra-cabeça com fotos antigas em uma praça pública. Após montarem, observaram o que ainda existe no local e o que existia anteriormente. Junto com o quebracabeça também se levaram fotos antigas em tamanho grande para facilitar a comparação.

Também se compartilhou com o grupo a metodologia utilizada na dissertação de mestrado desta autora: Refletindo sobre musealização - um encontro entre público e arqueologia marítima em Santos - SP. Na dissertação destacaram-se os temas: arqueologia, museologia, comunicação-recepção e educação. Nessa pesquisa, elaborou-se uma proposta de museu de arqueologia marítima para a cidade de Santos com a participação de alunos da rede municipal de ensino, da Escola Municipal Padre Lúcio Floro, localizada no Morro do José Menino em Santos- SP. Como ela fica localizada em um morro, é possível observar toda a Baía de Santos, o que facilitou compreender a relação da cidade com o mar, assunto mais estudado pelos estudantes ao longo da pesquisa. O período de intervenção junto ao grupo iniciou-se em fevereiro e foi até agosto de 2011.

Os temas estudados ao longo da investigação foram: museu, porto, arqueologia e arqueologia subaquática. A metodologia utilizada era uma mistura do Hereduc com o Método Paulo Freire (BRANDÃO, 2005), além de outros teóricos da educação.

Em cada etapa havia um ponto de entrada (para conhecer os conhecimentos prévios trazidos pelos estudantes), um enchendo sua mochila (em que se inteiravam do tema por meio de diversas atividades), um desenvolvendo uma solução (em que retomavam os conhecimentos para levantar novos aspectos) e resultados (que foi comum a todos os temas, por meio de um storyboard e uma roda de conversas). O objetivo não era analisar se as crianças aprenderam mais ou menos, mas coletar novos dados por meio de estratégias diferenciadas. 


\section{Revista de Arqueologia Pública}

Algumas das atividades desenvolvidas ao longo da pesquisa foram a caixa de objetos em que os estudantes escolhiam objetos e discutiam sobre uso, função e fabricação. Eles também observaram pranchas com fotos de metodologias de campo e laboratório e peças arqueológicas. As pranchas utilizadas foram desenvolvidas pelos setores educativos do Museu de Arqueologia e Etnologia da Universidade de São Paulo (MAE-USP) e do Museu de Arqueologia e Etnologia da Universidade Federal da Bahia (MAE-UFBA).

Ao longo das intervenções junto aos estudantes, houve a visita de dois especialistas. Uma delas foi a museóloga doutora Marília Xavier Cury falando sobre a elaboração da exposição Brasil 50.000, realizada em Brasília, em 2000. Ela levou a maquete e o catálogo da exposição e explicou sobre o processo de elaboração museológica.

Também se contou com a participação do arqueólogo doutor Paulo Bava de Camargo, que explicou sobre a pesquisa arqueológica dentro e fora d'água. Ele levou roupas de mergulho e os estudantes puderam manipular e experimentar algumas. Após o momento de exploração os alunos fizeram várias perguntas aos dois profissionais.

Encerrando o período de estudos de caso e iniciando um segundo momento, após os intervalos do curso, se praticava o "mão na massa". Tratava-se de uma atividade prática relacionada ao tema do dia. No primeiro encontro, observaram-se umas pranchas do MAEUSP para que cada um descrevesse a peça arqueológica da imagem selecionada tentando dizer de que locais elas eram. Foi uma atividade bem descontraída, em que um participante acabou auxiliando o outro na tentativa de decifrar seu objeto.

No segundo encontro, o tema foi educação patrimonial nos museus de arqueologia.

Historicamente, a educação patrimonial em museus tem sua ação pioneira no Museu Nacional, na década de 1940 (CAMPOS, 2014). A ação foi impulsionada pelo movimento da escola nova no Brasil (CUNHA, 1996), mas pouco se sabe sobre as práticas utilizadas no período. Mais tarde, as ações educativas em museus de arqueologia começaram a ser estruturadas no antigo Instituto de Pré - História da Universidade de São Paulo em 1979 (hoje MAE-USP) e no Museu do Sambaqui de Joinville em 1982, ambas ações estão ligadas ao trabalho da doutora Cristina Bruno.

A seguir, o segundo encontro prosseguiu com os estudos de caso das ações educativas do Museu de Arqueologia e Etnologia da Universidade de São Paulo (MAE-USP) e do Museu Arqueológico do Sambaqui de Joinville (MASJ). de São Paulo (MAE-USP) incluem: reserva técnica visitável, kits diversos, encontros de 


\section{Revista de Arqueologia Pública}

formação de professores, ações com a terceira idade, ações com a comunidade São Remo, entre outros.

Sobre as ações educativas no Museu do Sambaqui de Joinville, observam-se: sítio arqueológico experimental, atendimento educativo ao ensino formal (vencedor do Prêmio Rodrigo de Melo Franco, em 2008, na categoria educação patrimonial), além de kit didático, formação de professores, laboratório de experimentação e ações educativas com a comunidade in loco, em sítios arqueológicos da área urbana de Joinville-SC.

No terceiro encontro, o tema foi educação patrimonial na arqueologia de contrato. Nesse encontro tivemos um momento de compartilhar experiências, tendo em vista que todos os participantes eram arqueólogos e já possuíam conhecimentos na área da educação patrimonial. Foi uma ocasião muito importante, porque se discutiu problemas.

Os participantes do curso expuseram pontos fracos não só da educação patrimonial, mas da arqueologia de contrato como um todo, como pouco tempo, por exemplo.

Outro assunto levantado, em relação à educação patrimonial especificamente, foi que, muitos projetos são elaborados no Sudeste, com um perfil próprio e são aplicados no Nordeste (local onde o curso foi ministrado), sem levar em consideração diferenças locais.

Além dessas questões, ainda foram indicados os conhecidos problemas, de empresas que só distribuem folderes, ou fazem exposições de banneres e considera essas ações como programa de educação patrimonial.

Outro tema apontado pelo grupo foi a formação do arqueólogo em educação patrimonial, e como ela deveria ser obrigatória na graduação e pós-graduação, uma vez que a educação patrimonial é exigida em todos os trabalhos de arqueologia de contrato.

Nesse encontro, também se trabalhou com os bons exemplos de educação patrimonial na arqueologia de contrato. Para isso, recorremos a algumas dissertações e teses da Universidade de São Paulo, como exposto no início deste artigo.

O "mão na massa" desse último encontro foi o mais produtivo de todos. Esta autora foi surpreendida e por esse motivo esse artigo foi escrito. As atividades e reflexões fizeram pensar que organizar-se, tendo o olhar voltado para a educação patrimonial, obriga a reorganizar o planejamento da pesquisa arqueológica como um todo.

Após serem desafiados a elaborarem um planejamento de pesquisa arqueológica que considerasse a educação patrimonial como parte importante da pesquisa, o grupo criou ações que incluíam a educação, antes, durante e após as etapas de prospecção. Além dos escolares e de funcionários, as propostas integravam os grupos e as ações. Elas incluíam a comunidade como um todo.

\begin{tabular}{|l|l|l|l|l|l|l|}
\hline (C) Rev. Arqueologia Pública & Campinas, SP & v. 10 & n. 3 & p. 22-36 & OUT. 2016 & ISSN 2237-8294 \\
\hline
\end{tabular}




\section{Revista de Arqueologia Pública}

Ao longo da elaboração das propostas, pensava-se e discutia o tempo necessário para o desenvolvimento de estratégias mais complexas de educação e as possibilidades reais da aplicação de uma proposta mais abrangente.

\section{Considerações finais}

O tema do Congresso da Sociedade de Arqueologia Brasileira desse de 2015 foi Arqueologia para quem? Esta autora se indagou que a resposta pode ser: arqueologia também para arqueólogos.

Percebe-se que a educação patrimonial não é considerada por boa parte dos arqueólogos como arqueologia. $\mathrm{Na}$ verdade, ela faz parte do processo da pesquisa arqueológica sim, pelo viés da arqueologia pública. Assim como a museologia, a comunicação, o turismo e outras áreas que aproximam o público não acadêmico do saber arqueológico.

Essa valorização da educação patrimonial deve acontecer para que outros conheçam o trabalho dos arqueólogos e para que o patrimônio arqueológico brasileiro seja valorizado e protegido.

Além disso, é preciso ampliarr a visão. Ao falar de educação patrimonial, muitas vezes os profissionais se restringem ao público escolar e ao público infantil. Esses grupos são importantes, mas existe a necessidade de expandir as ações, atingindo outros públicos, como universitários de diversas áreas que dialogam com a arqueologia na prática como engenharia e arquitetura, e também educação, museologia, turismo, comunicação e outras. Quanto mais houver interação, mais a arqueologia será divulgada, bem como o saber construído por ela, principalmente nas contribuições às questões sociais.

Por fim, é preciso pensar que a educação patrimonial para arqueólogos é urgente e necessária. Essa formação deve acontecer nos cursos de graduação e de pós-graduação. Quando esse pensamento for recorrente, a arqueologia vai se fortalecer no Brasil e será realmente considerada por todos como imprescindível.

\section{Referências bibliográficas}

ALFONSO, Louise Prado. Arqueologia e turismo: sustentabilidade e inclusão social. Tese de Doutorado em Arqueologia. Museu de Arqueologia e Etnologia da Universidade de São Paulo, São Paulo, 2013. 
ALFONSO, Louise Prado e HATTORI, Márcia Lika. Diálogos e vínculos entre diferentes atores: por uma arqueologia mais colaborativa. In: Semana internacional de arqueologia 'andré penin' dos alunos de pós graduação do museu de arqueologia e etnologia - USP, 3, 2013, São Paulo. Caderno de Resumos: comunicações. São Paulo: MAE USP, 2013, p. 40.

ALMEIDA, Márcia Bezerra de. 0 australopiteco corcunda: as crianças e a Arqueologia em um projeto de Arqueologia Pública na escola. Tese de Doutorado em Arqueologia. Faculdade de Filosofia, Letras e Ciências Humanas da Universidade de São Paulo, São Paulo, 2002.

AMARANTE, Cristiane Eugênia. Refletindo sobre musealização: um encontro entre público e arqueologia marítima em Santos. Dissertação de Mestrado em Arqueologia. Museu de Arqueologia e Etnologia da Universidade de São Paulo, São Paulo, 2015.

BRANDÃO, Carlos Rodrigues. O que é método Paulo Freire. São Paulo: Brasiliense, 2005.

BRUNO, Maria Cristina Oliveira. O Museu de Pré-História: um museu a serviço da pesquisa científica. Dissertação de Mestrado em História Social. Faculdade de Filosofia, Letras e Ciências Humanas, Universidade de São Paulo, São Paulo, 1984.

Arqueologia e antropofagia: a musealização dos sítios arqueológicos. Revista do Instituto do Patrimônio Histórico e Artístico Nacional, Rio de Janeiro, v. 31, 2005, p. 234-247.

CARNEIRO, Carla Gibertoni. Ações educacionais no contexto da arqueologia preventiva: uma proposta para a Amazônia. Tese de Doutorado em Arqueologia - Museu de Arqueologia e Etnologia da Universidade de São Paulo, São Paulo, 2009.

CORDEIRO, Silvio L. A paisagem histórica do Engenho São Jorge dos Erasmos: o vídeo como instrumento educativo na arqueologia do monumento quinhentista. Dissertação de Mestrado em Arqueologia. Museu de Arqueologia e Etnologia da Universidade de São Paulo, São Paulo, 2007.

CUNHA, Marcus Vinicius da. Dewey e Piaget no Brasil dos anos trinta. Caderno de Pesquisa, São Paulo, n. 97, p. 5 - 12, mai. 1996.

CURY, Marília Xavier. Comunicação museológica: uma perspectiva teórica e metodológica de recepção. Tese de Doutorado. Escola de Comunicação e Artes da Universidade de São Paulo, São Paulo, 2005.

Para saber o que o público pensa sobre arqueologia. Revista Arqueologia Pública, São Paulo, n¹, 2006, p. 31-48.

DEWEY, Jonh. A criança e os programas de ensino. Educação, São Paulo, n. 4/5, p. 115 131, abr./mai. 1932.

. Vida e Educação. $7^{a}$ ed. São Paulo: Melhoramentos, 1971.

DUARTE, Ana. Educação Patrimonial: guia para professores, educadores e monitores de museu e tempos livres. 2. ed. Lisboa: Texto Editora, 1994. 


\section{Revista de Arqueologia Pública}

FERNANDES, Tatiana Costa. Vamos criar um sentimento? Um olhar sobre Arqueologia Pública no Brasil. Dissertação (Mestrado). Museu de Arqueologia e Etnologia da Universidade de São Paulo, São Paulo, 2007.

FREIRE, Paulo. Pedagogia do oprimido, 17ạ. ed. Rio de Janeiro, Paz e Terra, 1987. Pedagogia da Autonomia - Saberes necessários a prática educativa. São Paulo, Brasil: Paz e Terra (Coleção Leitura), 1997.

FUNARI, P. P. Arqueologia Brasileira: visão geral e reavaliação. P.24-41, 1994. FUNARI, Pedro Paulo e PELEGRINI, Sandra C. A. Patrimônio Histórico e Cultural. Rio de Janeiro: Jorge Zahar, 2006.

HERNANDEZ, Fernando; VENTURA, Montserrat. A organização do currículo por projetos de trabalho. Porto Alegre. Artes Médicas, 1998a.

Transgressão e mudança na educação. Porto Alegre. ARTMED, 1998b.

HORTA, Maria de Lourdes Parreiras, GRUNBERG, Evelina e MONTEIRO, Adriane Queiroz. Guia básico de educação patrimonial. Brasília: Museu Imperial/IPHAN/MinC, 1999.

LIMA, Leilane Patrícia de. Entre os caminhos da Arqueologia Pública e da Educação: um estudo de caso a partir de uma proposta educativa para as séries iniciais do ensino fundamental em Londrina / PR. Tese de Doutorado em Arqueologia. Museu de Arqueologia e Etnologia da Universidade de São Paulo, São Paulo, 2015.

MERRIMAN. Nick. Public Archaeology. Published by: Taylor \& Francis, 2004.

MORAES WICHERS, Camila Azevedo de. Patrimônio Arqueológico Paulista: proposições e provocações museológicas. Tese de Doutorado em Arqueologia. Museu de Arqueologia e Etnologia da Universidade de São Paulo, São Paulo, 2011.

PIAGET, Jean. A construção do real na criança. 2a. ed. Rio de Janeiro, Zahar, 1974. de Cultura, 1973.

A linguagem e o pensamento da criança. 3á ed. Rio de Janeiro, Fundo

A formação do símbolo na criança: imitação, jogo e sonho, imagem e representação. Rio de Janeiro, Zahar, 1971.

O raciocínio na criança. $3^{\underline{a}}$ ed. Rio de Janeiro, Record, 1967.

O nascimento da inteligência na criança. Rio de Janeiro, Zahar, 1966.

SILVA, Maurício André da. Memórias e histórias no sudoeste amazônico: o Museu Regional de Arqueologia de Rondônia. Dissertação de Mestrado em Arqueologia. Museu de Arqueologia e Etnologia da Universidade de São Paulo, São Paulo, 2015.

TAMANINI. Elizabete. Museu Arqueológico de Sambaqui de Joinville: um olhar necessário. Dissertação de Mestrado em Educação. Universidade Estadual de Campinas, Campinas, 1994. 


\section{Revista de Arqueologia Pública}

TAUHYL, Ana Paula Moreli. Alfabetização do olhar: aprender pelos objetos e suas representações. Dissertação de Mestrado em Arqueologia. Museu de Arqueologia e Etnologia da Universidade de São Paulo, São Paulo, 2013.

TROYLER, Veerle De (org). Heritage in the classroom: a practical manual for teachers (the complete book). Het Gemeenschapsonderwijs: Internationalisation Departmentent, 2005. Disponível em: <http://www.hereduc.net/hereduc/i18nfolder.2005-0415.8911096798/>. Acesso em: 04 dez. 2010.

VYGOTSKY, Lev S. Pensamento e Linguagem. Rio de Janeiro: Martins Fontes, 1998.

A formação social da mente. Rio de Janeiro: Martins Fontes, 1996. 